This item was submitted to Loughborough's Research Repository by the author.

Items in Figshare are protected by copyright, with all rights reserved, unless otherwise indicated.

\title{
Finite element analysis of forces of plane cutting of cortical bone
}

PLEASE CITE THE PUBLISHED VERSION

PUBLISHER

(C) Elsevier

VERSION

AM (Accepted Manuscript)

LICENCE

CC BY-NC-ND 4.0

\section{REPOSITORY RECORD}

Alam, Khurshid, A.V. Mitrofanov, and Vadim V. Silberschmidt. 2019. "Finite Element Analysis of Forces of Plane Cutting of Cortical Bone". figshare. https://hdl.handle.net/2134/5253. 
This item was submitted to Loughborough's Institutional Repository (https://dspace.lboro.ac.uk/) by the author and is made available under the following Creative Commons Licence conditions.

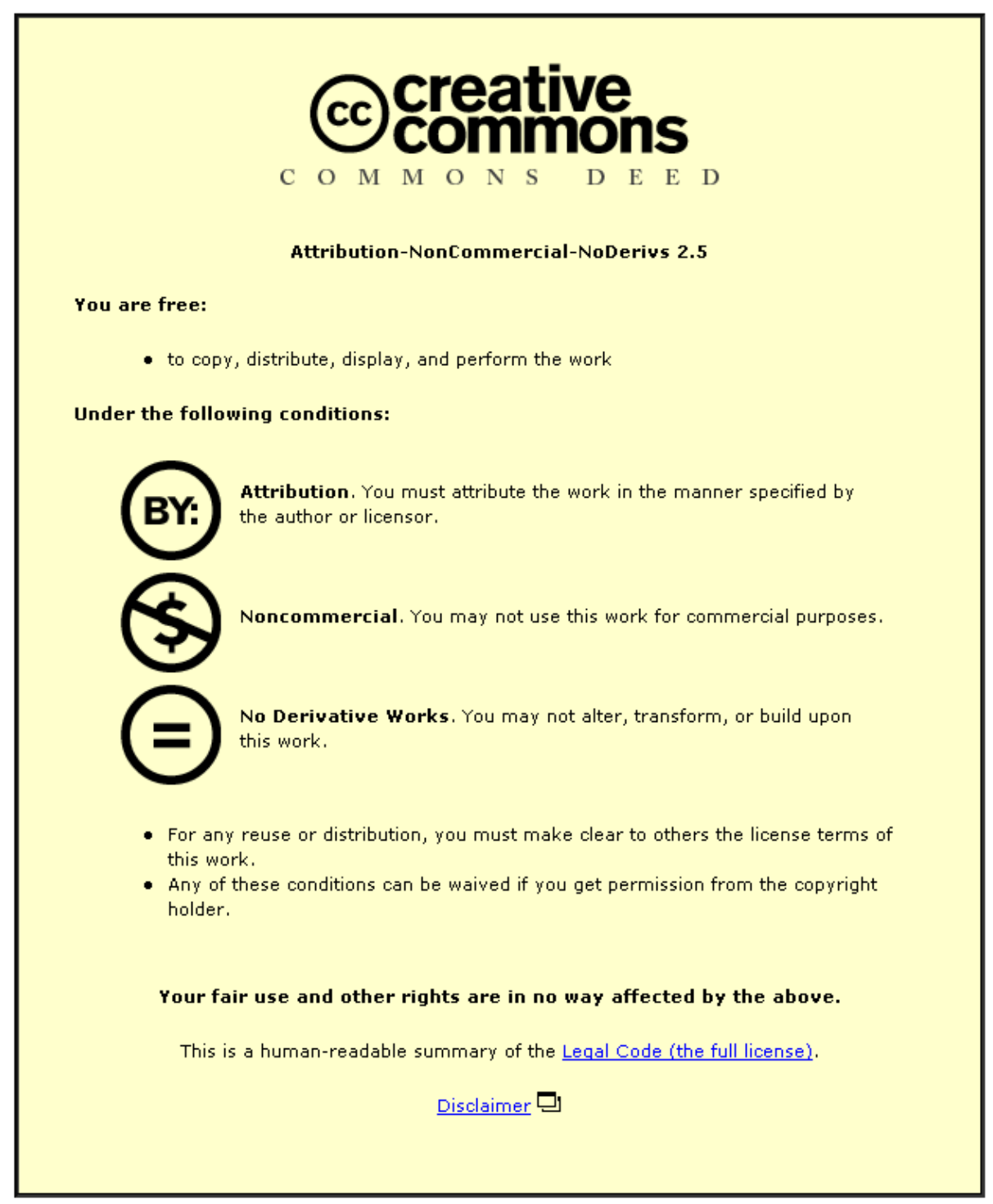

For the full text of this licence, please go to: http://creativecommons.org/licenses/by-nc-nd/2.5/ 


\title{
Finite element analysis of forces of plane cutting of cortical bone
}

\author{
K. Alam, A.V. Mitrofanov, V.V. Silberschmidt \\ Wolfson School of Mechanical and Manufacturing Engineering, Loughborough \\ University, LE11 3TU, UK
}

\begin{abstract}
Bone cutting is an essential part of orthopaedic surgery when bone is fractured or damaged by a disease and is used for pins insertion and plates fixation. A finite element model of bone cutting is developed and compared with experimental results. The model allows the interaction between the bone and cutting tool to be studied, hence enabling the evaluation and optimization of the cutting procedure. Results of finite element simulations are obtained for the cutting force as a function of cutting parameters. A strong dependence of cutting parameters on the cutting force was found and described in this paper.
\end{abstract}

Keywords: FE modelling; bone cutting; cutting force analysis; material properties of bone

\section{Introduction}

Mechanical operations performed on the bone tissue as a part of surgical procedures are similar to those conducted with structural materials, for example, drilling, reaming and sawing. Reduction of surgery time and improving precision of cutting are major concerns in modern-day orthopaedics. In orthopaedic bone cutting it is also desirable to control the level of cutting forces to enable smooth penetration of a surgical instrument 
and to avoid unnecessary damage to soft tissues surrounding the bone. To achieve this, various technological improvements have been introduced in cutting procedures as well as in cutting tools. Novel drilling methods are constantly introduced in orthopaedic, neuro and dental surgeries and are aimed at minimizing the invasiveness and improving the safety of the operation.

Previous research conducted in this area was mainly experimental. Matthews and Hirsch [1] studied the effect of rotational speed and thrust forces on bone temperature in orthopaedic bone drilling. Jacobs et al. [2] measured the torque and thrust forces for different drill point configurations at various levels of constant feed rate and rotational speed. They found that the drill point geometry was critical to minimize the drilling forces. Pal and Saha [3] and Saha et al. [4] reported on an improved drill, which minimized the thrust force and provided effective removal of bone chips. It was noted that drilling a predrilled hole (as in reaming) significantly reduced the thrust forces due to the elimination of the chisel edge thrust at the tip of the drill.

The efficiency of the cutting operation can be determined from the amount of work required to cut the material as defined by Merchant [5, 6] and Ernst [7]. This analysis was shown to be valid for bone cutting by Jacobs et al. [8], Krause [9] and Wiggins and Malkin [10]. In those studies, the cutting processes on bone were studied and parameters, affecting mechanics of bone cutting were described. Krause [9] investigated the effect of cutting speed on cutting forces. It was reported that increasing the cutting speed decreased the cutting forces and specific cutting energy; that was attributed to the change in the frictional behaviour between the tool and bone when the cutting speed was increased. 
Optimization of cutting parameters is necessary to improve bone cutting methods. Presently, this requires expensive experimental equipment and additional safety measures to protect from biohazards. Finite element (FE) modelling of bone cutting could be an important extension to, and possible substitute for, experimental work as it eliminates high costs for the experimental equipment as well as potential health risks associated with biological materials. FE modelling of bone cutting has not been reported in the literature so far. The studies have been limited to FE cutting models for materials similar to bone such as E-glass filled epoxy resin, polyurethane foam and wood [11, $12]$.

\section{Numerical model}

\subsection{FE formulation}

MSC Marc general FE code [13] was used in the development of our two-dimensional FE model of bone cutting. A rectangle part of the bone was modelled with dimensions 4 $\mathrm{mm} \times 2 \mathrm{~mm}$. In cutting simulations the workpiece was stationary and the tool was moving with a constant velocity. The workpiece was discretized into four-node, isoparametric, arbitrary quadrilateral elements assuming plane strain conditions. The cutting tool was modelled with isoparametric triangular elements. Frequent remeshing was applied to avoid convergence issues associated with highly distorted elements. Constraints on workpiece elements were not feasible in the presence of remeshing due to the software limitations. To resolve this, rigid lines AD, DC and CE (see Fig. 1a) were created at the left, bottom and right of the work piece and were permanently "glued" to it. Mechanical boundary conditions were applied at those lines, which were transferred to the workpiece elements. The depth of cut (DOC) was varied in 
simulations by changing the vertical position of the tool. The initial FE mesh and the applied boundary conditions are shown in Fig. 1b.

The FE model presupposes formation of a continuous chip, which is in good agreement with the results of our high-speed filming experiments of bone drilling as well other experimental studies, e.g. on cutting of a pig cortical bone [14] and endmilling [15].

All the simulations were continued till full chip formation, i.e. stabilisation of cutting forces, stresses and strains caused by the cutting process. The shear friction model [13] that is frequently used for modelling of cutting processes was chosen for simulations since the classical Coulomb model is unable to adequately reflect friction processes in cutting due to the generation of high contact stresses at a tool-chip interface leading to overestimation in friction forces.

\subsection{Material data}

Bone is a heterogeneous material and can be approximated as a fibre-reinforced composite. Simplifying fibre-reinforced composite as equivalent heterogeneous material (EHM) at the length scale larger than the characteristic length of a microstructure (e.g., a size of the representative volume element) for modelling purposes is a common practice. So, the bone was approximated as EHM at this stage of our simulations. To obtain mechanical parameters for the model, mid-diaphysis of a fresh bovine femur (age 3-4 years) was used in all experiments. This type of bone was of interest since, according to [16], its mechanical, fracture and thermal properties are similar to those of a human bone. The tested specimens were visibly free from osteopenia and musculoskeletal disease. Nanoindentation tests were carried out at osteonal and interstitial bone. A total of 40 indents were made with 20 indents in each phase. The average values of elastic modulus for osteonal and interstitial bone were $18 \mathrm{GPa}$ and 22 
$\mathrm{GPa}$, respectively. A microscopic image of $1 \mathrm{~mm} \times 1 \mathrm{~mm}$ of bone cross-section was taken and the ratio of the osteonal area to the interstitial area was found. The rule of mixtures was used to calculate the effective elastic modulus of the equivalent homogeneous material; the obtained magnitude - $20 \mathrm{GPa}$ - was incorporated into our FE model.

To describe a non-elastic behaviour of the bone tissue, the Johnson-Cook (JC) material model that accounts for non-linear strain hardening and strain-rate sensitivity was utilised. In this model, the bone is considered as an elastic-plastic material with bilinear strain hardening. The JC material model, widely used in metal cutting simulations [17, 18], was introduced in the following form:

$$
\sigma_{\mathrm{Y}}=\left(A+B \varepsilon_{\mathrm{p}}^{n}\right)\left(1+C \ln \left(\frac{\dot{\varepsilon}_{p}}{\dot{\varepsilon}_{\mathrm{o}}}\right)\right)
$$

where $A, B, C, n$ are constants; $\varepsilon_{p}$ and $\dot{\varepsilon}$ are the plastic strain and strain rate, respectively. The effects of temperature on $\sigma_{\mathrm{Y}}$ was not considered in the simulations due to small temperature changes - the maximum temperature observed in the material was about $80^{\circ} \mathrm{C}$ - with no significant thermal effects expected in this range.

To determine a strain rate dependency of the bone material, 30 dogbone type specimens were extracted from the mid-diaphysis of the femur bone. The specimens were tested for three strain rates between $0.00001 \mathrm{~s}^{-1}$ to $1 \mathrm{~s}^{-1}$ with 10 samples for each strain rate. The specimens were kept wet during the test with cold water spray. The yield stress increased by $72 \%$ (from $58 \mathrm{MPa}$ and $101 \mathrm{MPa}$ ) as the strain rate was changed from $0.00001 \mathrm{~s}^{-1}$ to $0.001 \mathrm{~s}^{-1}$. The additional increase for the change in strain rate from $0.001 \mathrm{~s}^{-1}$ to $1 \mathrm{~s}^{-1}$ was below $5 \%$. Based on results of those experiments it was assumed that $\mathrm{t}$ the effect of strain rates higher than $1 \mathrm{~s}^{-1}$ can be neglected. The JC constants were then 
calculated by fitting the equation into the stress-strain graphs obtained from the tension tests on the bone as shown in Fig. 2; their magnitudes used in simulations are given in Table 1.

In numerical studies, material separation ahead of the tool occurred when the breaking stress (obtained from the tensile test) was reached as shown in Fig. 3.

\subsection{Cutting parameters}

Mechanical drills are the most commonly used tools in bone surgeries. The FE modelling of the drilling process is a complex matter and the cutting may be approximated as a 2D process at the outer corner of the cutting lip [19]. The diameter of the drill used in actual orthopaedic bone drilling is generally $2-4 \mathrm{~mm}$ with rotational speeds from $1000 \mathrm{rpm}$ to $2000 \mathrm{rpm}$. These parameters were chosen as recommended and they are widely reported in literature for drilling of bones [20, 21]. The range of the speeds considered in numerical simulations representing conditions of real-life bone surgery (denoted I in Table 2) was calculated as a conversion of the rotational speed into linear speed at the outer corner of the drill lip for the maximum drill speed and drill diameter (i.e. $2000 \mathrm{rpm}$ and $4 \mathrm{~mm}$, respectively). As the exact frictional condition between the tool and bone was unknown, the value of friction coefficient $(0.35)$ was taken from [22] due to the similarity in the chip formation behaviour between bone and wood

The value of the cutting edge angle and rake angle of an orthopaedic drill were measured and found $60^{\circ}$ and $20^{\circ}$, respectively, and were used in modelling the cutting tool. The nose radius of the sharp edge of the tool used in plane cutting experiments was defined as approximately 10 micrometers from a microscopic image. The maximum 
value of DOC $-0.3 \mathrm{~mm}$ - was chosen in plane cutting experiments as above this value the generated chips were no longer continuous. That allowed a comparison between the numerical and experimental levels of the force for a similar chip shape. It is worth mentioning that the DOC produced by the five clinicians was between $0.1 \mathrm{~mm}$ and 0.3 $\mathrm{mm}$ in studies into the level of force produced when cutting the bone with chisel and conventional bur [23]..

In numerical simulations, parameters such as the DOC, nose radius $(\Phi)$ and cutting velocity were changed to observe their effect on cutting forces. All cutting parameters used in simulations and experiments are given in Table 2.

\section{Results of FE Simulations}

\subsection{Cutting force analysis}

The main focus of simulations was on assessment of the levels of cutting forces that represent in an integral force the result of interaction between a tool and a bone for a given set of cutting parameters. Low-level fluctuations of the cutting force were observed in simulations, which are attributed to the remeshing as well as numerical errors inherent to FE simulations (Fig. 4). This level of fluctuations can be reduced further by using the finer mesh size in the tool-work piece interaction zone and also by increasing the number of increments and introducing more remeshing cycles between increments. A denser mesh will, however, require considerable computational power and memory. The force at peak value was therefore smoothed in presenting graphically the obtained results to eliminate those low-level fluctuations. The FE model was validated by comparing the calculated results for the cutting force with those obtained from experiments (see below). The software has the capability to combine all the forces 
on the tool nodes and resolve to a single point, normally a centroid of the body [14]. In all these simulations the forces developed rapidly (within $0.05 \mathrm{~ms}$ ) and achieved saturated levels at approx. $0.2 \mathrm{~ms}$; that level remained nearly constant in simulations for the remaining length of cut.

Several case studies were implemented to analyse the effect of various parameters on the level of cutting forces. Their results are presented below.

\section{Effect of DOC on cutting force}

The obtained results of simulations showed a significant difference in forces acting on the cutting tool when the DOC was varied. An increase of $66 \%$ in the cutting force was observed when the DOC was increased from $0.1 \mathrm{~mm}$ to $0.2 \mathrm{~mm}$. Another $62 \%$ increase resulted from the DOC change from $0.2 \mathrm{~mm}$ to $0.3 \mathrm{~mm}$. The increase in cutting force was due to the fact that the tool had to remove more material from the workpiece at the higher DOC with increased resistance. The increase in the amount of friction (due to larger tool-work contact) was another contributing factor. The magnitudes of the longitudinal cutting force for various levels of DOC are shown in Fig. 5.

\section{Effect of tool velocity on cutting force}

To account for the change in the cutting force with an increase in the material removal rate, the tool speed was varied from $50 \mathrm{~mm} / \mathrm{s}$ to $400 \mathrm{~mm} / \mathrm{s}$. The cutting forces remained almost unchanged for the entire range of rates. The cutting force was also observed to be unaffected by the range of velocities used in experiments (Table 2).

\subsubsection{Effect of lubrication on cutting force}


The exact definition of frictional interaction between a bone and cutter is not reported in the literature. A significant difference was observed in forces in the cutting tool when the friction coefficient was increased from $\mu=0$, i.e. frictionless conditions, to lubricated cutting, $\mu=0.35$. The cutting force magnitudes in simulations with and without friction are shown in Fig. 6. An increase of $40 \%$ was observed with introduction of friction for DOC $=0.3 \mathrm{~mm}$, whereas at the lower DOC $(0.1 \mathrm{~mm})$ an increase of $58 \%$ was noted.

\subsubsection{Effect of tool nose radius $(\Phi)$ on cutting force}

The tool nose radius $\Phi$ was changed from 0 to $15 \mu \mathrm{m}$ in simulations. The comparison of forces acting on the cutting tool is shown in Fig. 7. The force increased by a considerable amount with increasing the nose radius. The cutting force increases by $37 \%$ when tool nose radius is increased from 0 to $15 \mu \mathrm{m}$. A sharp edge of the tool causes stress concentration in work piece elements hence enabling the tool to penetrate with less energy. In the case of a larger edge radius, more elements come into contact with the curved edge and higher energy is required for penetration.

\section{Model validation}

To validate the developed model of bone cutting, experimental measurements of cutting forces for a real bone tissue were conducted. The bone used in plane cutting experiments was from the same animal and anatomical location as investigated in the material data acquisition tests. The natural shape of the bone was not suitable to be gripped in a holding device for plane cutting. To eliminate this problem the bone middiaphysis was cut into two parts along its longitudinal axis. One portion of the bone was glued to the surface of a metal block with David Isopon P40 kit with the bone top 
surface facing the tool. In the experiments, the workpiece was fixed in a holder and mounted on a force dynamometer. The metal block was then gripped firmly in a fixture. The surface of bone was not flat due to the change in bone diameter along bone axis, hence plane cutting operation across its surface was not possible. The shape/geometry of the bone is such that it can be used for plane cutting operation only along the longitudinal axis of bone. There was an additional problem since the diameter of the femur rapidly changed from the mid-diaphysis to metaphysis along the bone axis. It was resolved by milling the bone top surface on a $\mathrm{CNC}$ milling machine. An experimental setup for measuring the cutting force is shown in Fig. 8; the cutting parameters used in our experiments are provided in Table 3.

To compare the cutting forces obtained from the FE model with experimental results, an additional series of numerical simulations (denoted II in Table 1) was implemented for lower velocities (up to $16 \mathrm{~mm} / \mathrm{s}$ ) than usually used in surgery. This is the maximum speed that can be reached in the experiment to obtain the force data due to a short length of cut (about 50-60 $\mathrm{mm}$ ) across the bone surface available for plane cutting under those conditions. The cutting time (approximately 4 seconds at $16 \mathrm{~mm} / \mathrm{s}$ ) was sufficient to attain the stable cutting force that was measured using the force dynamometer.

No significant change in the cutting force was observed in the experiments for the chosen range of velocities (Table 2). Unlike simulations, the force measurements were limited to three values of the DOC as it was very difficult to control the exact depth within a narrow interval $-0.1 \mathrm{~mm}$ and $0.15 \mathrm{~mm}$-in real-life tests. Magnitudes of the cutting force obtained in experiments are shown in Fig. 9. A comparison of calculated and measured cutting forces is shown in Fig. 10 for three values of DOC. It is evident that two sets of results are in good agreement. A difference of $10 \%$ between the 
measured and predicted values was found for DOC up to $0.2 \mathrm{~mm}$ and could be attributed to the simplified model pof bone material used at this stage of our studies..

\section{Conclusions}

A finite element model of bone cutting was developed that is capable of predicting the cutting forces for various process parameters. The JC material model was used in the cutting simulations; its constants were obtained from tension tests at different strain rates. The level of cutting force was affected by tool geometry and the depth, at which the tool cuts the bone in numerical simulations. The material removal rate and extent of lubrication are the main factors responsible for the variation of the cutting force. This research is an attempt to provide basic understanding of the relationship between the process parameters and tool geometry, on the one hand, and the cutting force, on the other. This information can be used to optimize bone surgery in order to achieve minimum invasion. From this study, the low depth of cut and cutting tool with the sharp edge, which reduces the cutting forces, can be recommended for orthopaedic bone surgery. A more advanced FE model of bone cutting will be produced at the next stage of research, which will take into account bone anisotropy and will be supported by a more advanced material model. With regards to this, a series of tests to investigate the fracture properties and crack monitoring ahead of a sharp edge using X-ray microcomputer tomography is currently carried out.

\section{References}


[1] L.S. Matthews, C. Hirsch, Temperatures measured in human cortical bone when drilling, J. Bone. Joint. Surg. 54A (1972) 297-308.

[2] C.H. Jacobs, J.T. Berry M. H. Pope, F. T. Hoaglund, A study of the bone machining process drilling, J. Biomech. 9 (1976) 343-344.

[3] S. Pal, S. Saha, Analysis and performance of a new improved surgical drill, Advances in Bioengineering. ASME (1981) 51-53.

[4] S. Saha, S. Pal, J.A. Albright, Surgical drilling design and performance of an improved drill, J. Biomech. Eng. 104 (1982) 245-252.

[5] M.E. Merchant, Basic mechanics of the metal cutting process, J. Appl. Mech. 11A (1944) 168-175.

[6] M.E. Merchant, Mechanics of the metal cutting process - I. Orthogonal cutting and a Type 2 chip, J. Appl. Phys. 16 (1945) 267-275.

[7] H. Ernst, Physics of metal cutting, Machining of metals. Cleveland, ASM (1938).

[8] C.H. Jacobs, M.H. Pope, J.T. Berry, F.T. Hoagland, A study of the bone machining process - Orthogonal cutting, J. Biomech. 7(2) (1974) 131-132.

[9] W.R. Krause, Mechanical effects of orthogonal bone cutting, Ph.D Thesis, Clemson University, 1976.

[10] K.L. Wiggings, S. Malkin, Orthogonal machining of bone, J. Biomech. Eng. 100 (1978) 122-130.

[11] M. Lucas, A. MacBeath, E. McCulloch, A. Cardoni, A finite element model for ultrasonic cutting, Ultrasonics. 44 (2006) 503-509.

[12] L. Lan, H. McCallion, A cellular finite element model for the cutting of softwood across the grain, Int. J. Mech. Sci. 42 (2000) 2283-2301. 
[13] MSC. Marc User's Guide, Version 2007. MSC Software Corporation, Los Angeles, 2007.

[14] S. Naohiko, M. Mamoru, F. Yoshinori, S. Tadaaki, Relationship between anisotropic tissue and cutting stress characteristics in pig cortical bone, J. Jap. Soc. Adv. Prod. Tech. 24 (2006) 8-13.

[15] M. Mitsuishi, S. Warisawa, N. Sugita, Determination of the machining characteristics of a biomaterial using a machine tool designed for Total Knee Arthroplasty, CIRP Annals - Manuf. Technol.. 53 (2004) 107-112.

[16] D. Vashishth, K.E. Tanner, W. Bonfield, Contribution, development and morphology of microcracking in cortical bone during crack propagation, J. Biomech. 33 (2000) 1169-1174.

[17] A.V. Mitrofanov, V.I. Babitsky, V.V. Silberschmidt, Finite element analysis of ultrasonically assisted turning of Inconel 718, J. Mat. Proc. Tech. 153-154 (2004) $233-239$

[18] N. Ahmed, A.V. Mitrofanov, V.I. Babitsky, V.V. Silberschmidt, Analysis of forces in ultrasonically assisted turning, J. Sound Vib. 308 (2007) 845-854.

[19] B. Ozcelik, E. Bagci, Experimental and numerical studies on the determination of twist drill temperature in dry drilling: A new approach, J. Mat. Design. 27 (2006) $920-927$.

[20] M.T. Hillery, I. Shuaib, Temperature effects in the drilling of human and bovine bone, J. Mater. Proc. Tech. 92-93 (1999) 302-308.

[21] K. N. Bachus, M T Rondina, D T Hutchinson: The effects of drilling force on cortical temperatures and their duration: an in vitro study. Med. Eng. Phy. 22(10) (2000) 685-691. 
[22] Y. Huang, S.Chen, J.Tang, Analyses of rotating disc cutting of wood, Taiwan J. For. Sci. 18(4) (2003) 263-271.

[23] B.S. Khambay, A.D.Walmsley, Investigations into the use of an ultrasonic chisel to cut bone. Part 1: forces applied by clinicians, J. Dent. 28(1) (2000) 31-37. 


\begin{tabular}{llll}
$A(\mathrm{MPa})$ & $B(\mathrm{MPa})$ & $C$ & $n$ \\
\hline 50 & 101 & 0.03 & 0.08
\end{tabular}

Table 1 


\begin{tabular}{lcc}
\hline \multirow{2}{*}{ Parameters } & \multicolumn{2}{c}{ Magnitudes of parameters } \\
\cline { 2 - 3 } & Experiments & FEA \\
\hline Cutting speed $(\mathrm{mm} / \mathrm{sec})$ & $4 ; 8 ; 12 ; 16$ & (I) $100 ; 150 ; 200 ; 250 ; 300 ; 350 ; 400$ \\
\hline Friction coefficient & ---- & $(\mathrm{II}) 4 ; 8 ; 12 ; 16$ \\
\hline Tool nose radius, $\Phi(\mu \mathrm{m})$ & 10 & $0 ; 0.35$ \\
\hline DOC $(\mathrm{mm})$ & $0.1 ; 0.2 ; 0.3$ & $0.1 ; 0 ; 10 ; 15$ \\
\hline Tool rake angle, $\gamma(\mathrm{deg})$ & 20 & 20 \\
\hline
\end{tabular}

Table 2 


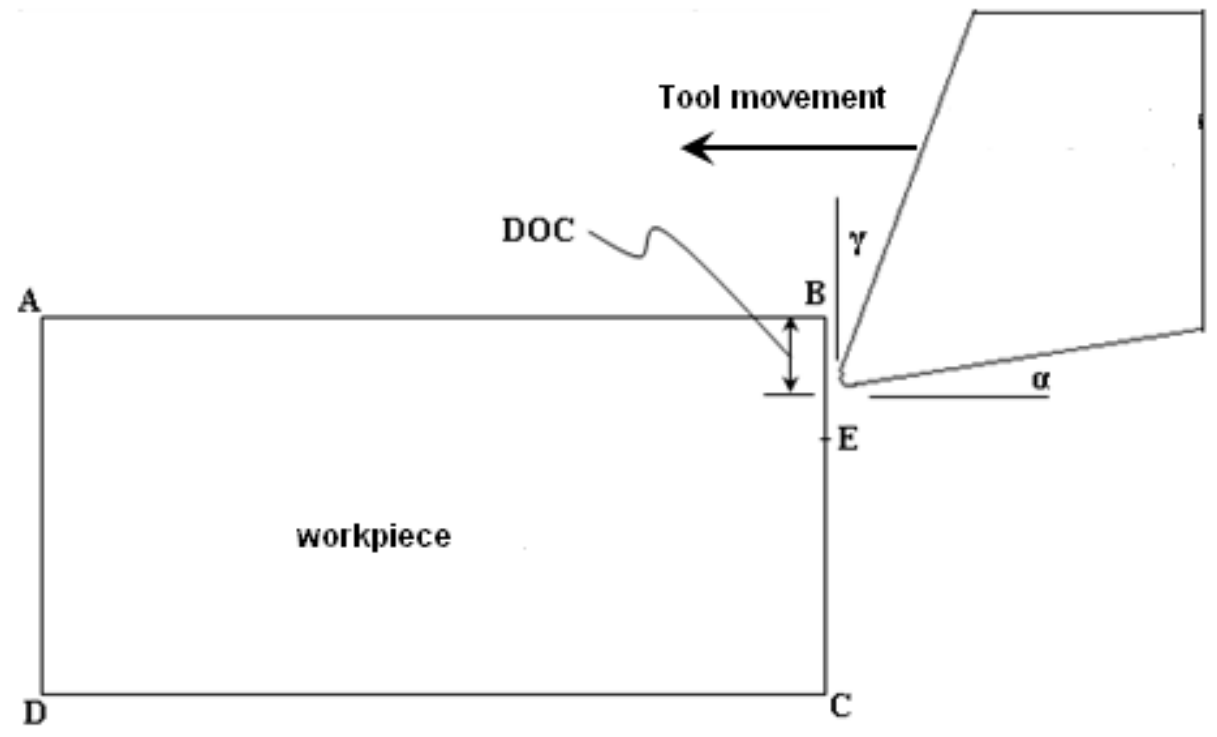

(a)

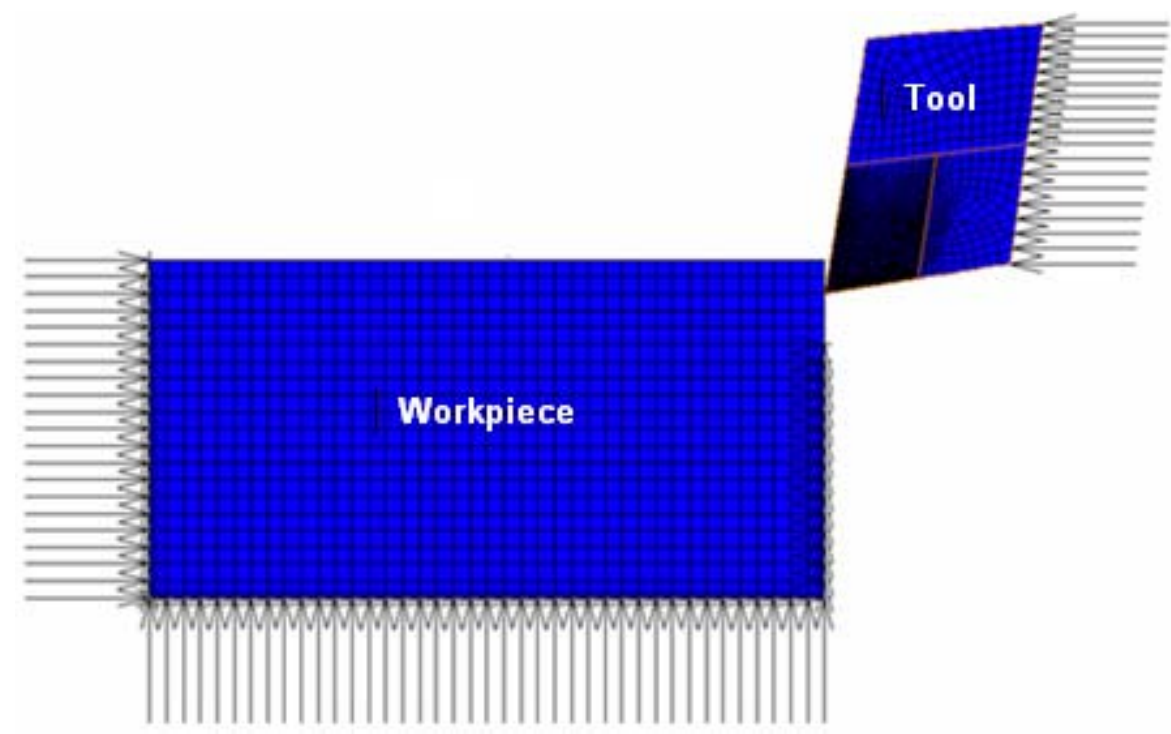

(b) 
Fig. 1 


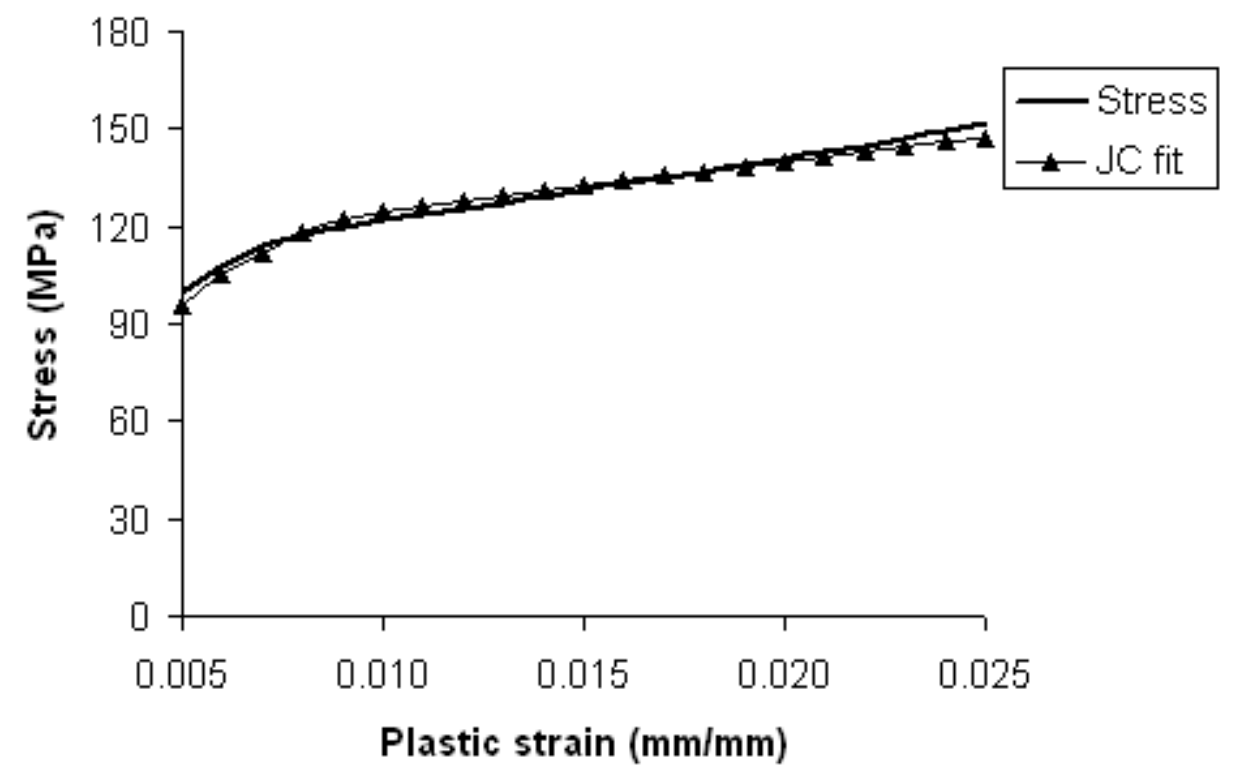

Fig. 2 


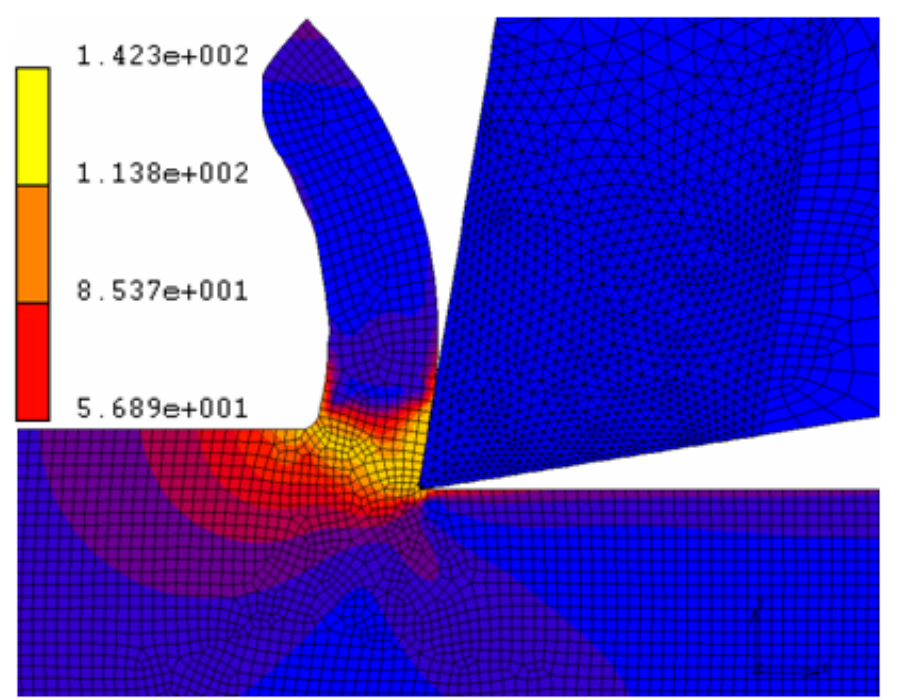

Fig. 3 


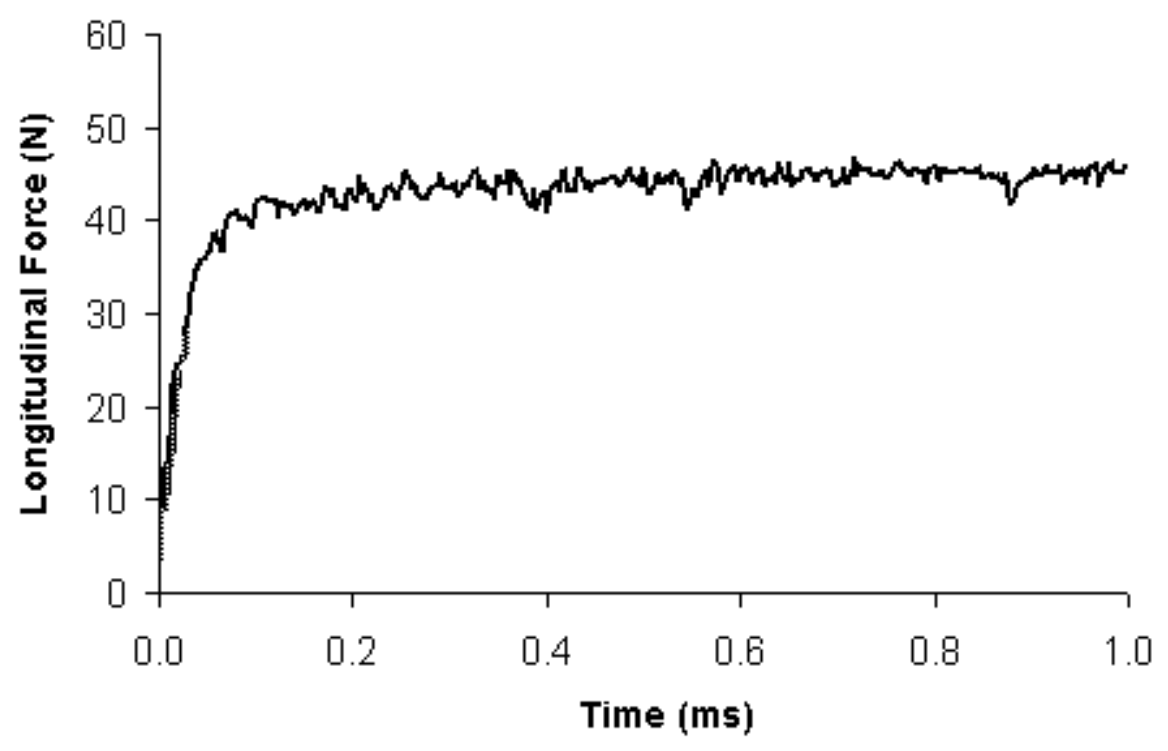

Fig. 4 


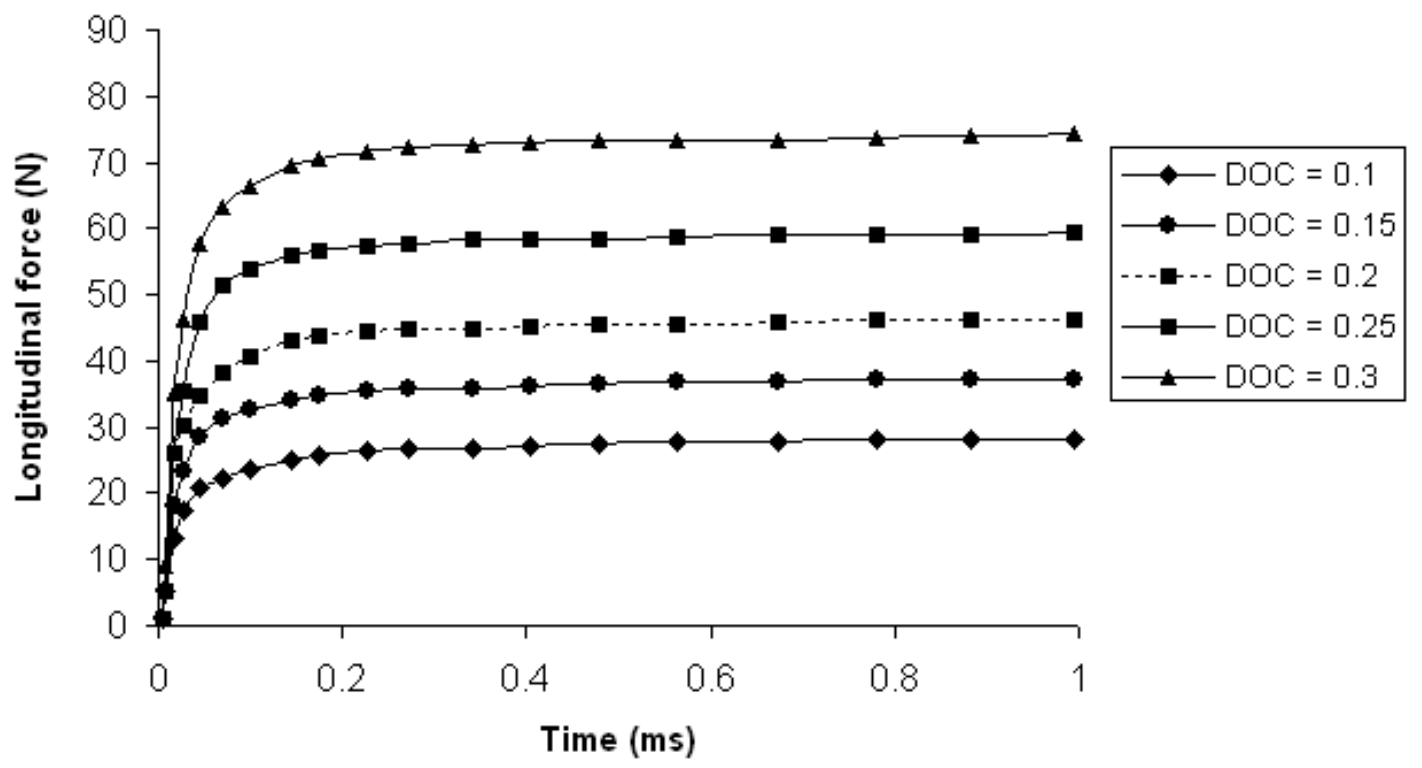

Fig. 5 


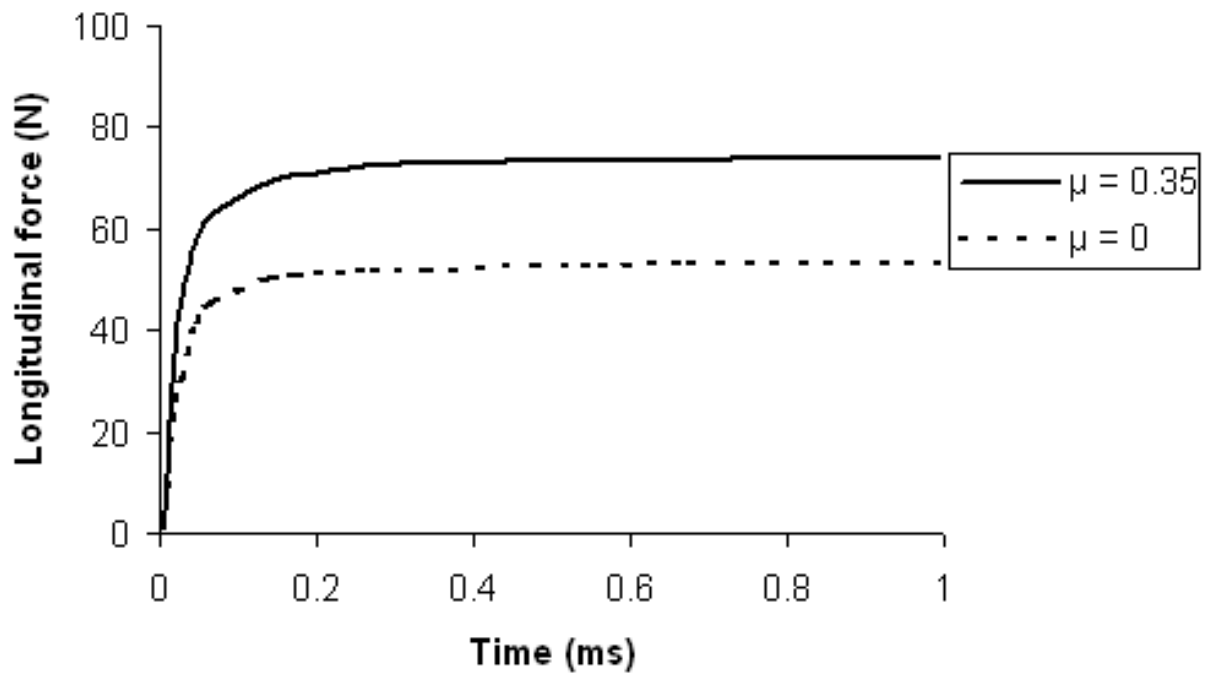

Fig. 6 


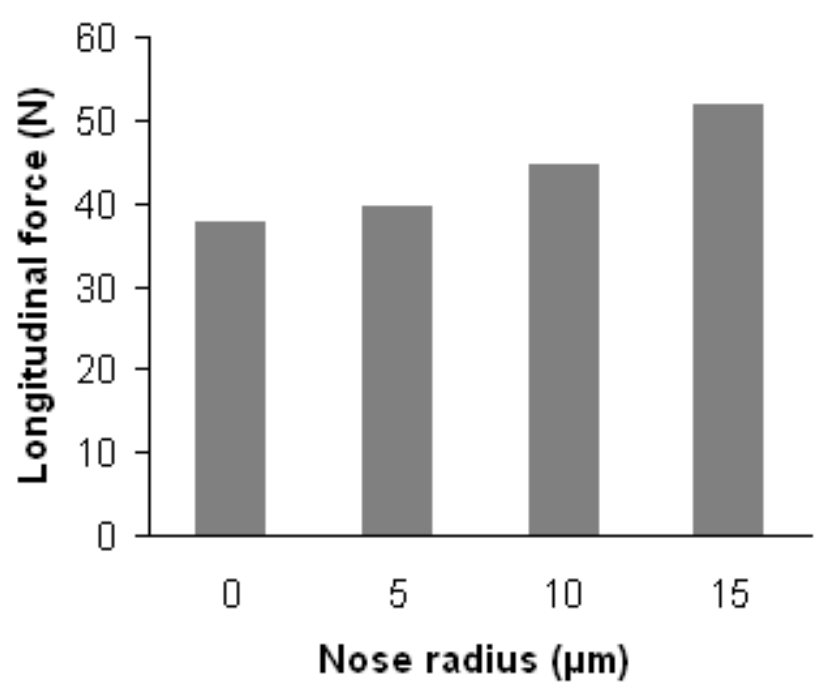

Fig. 7 


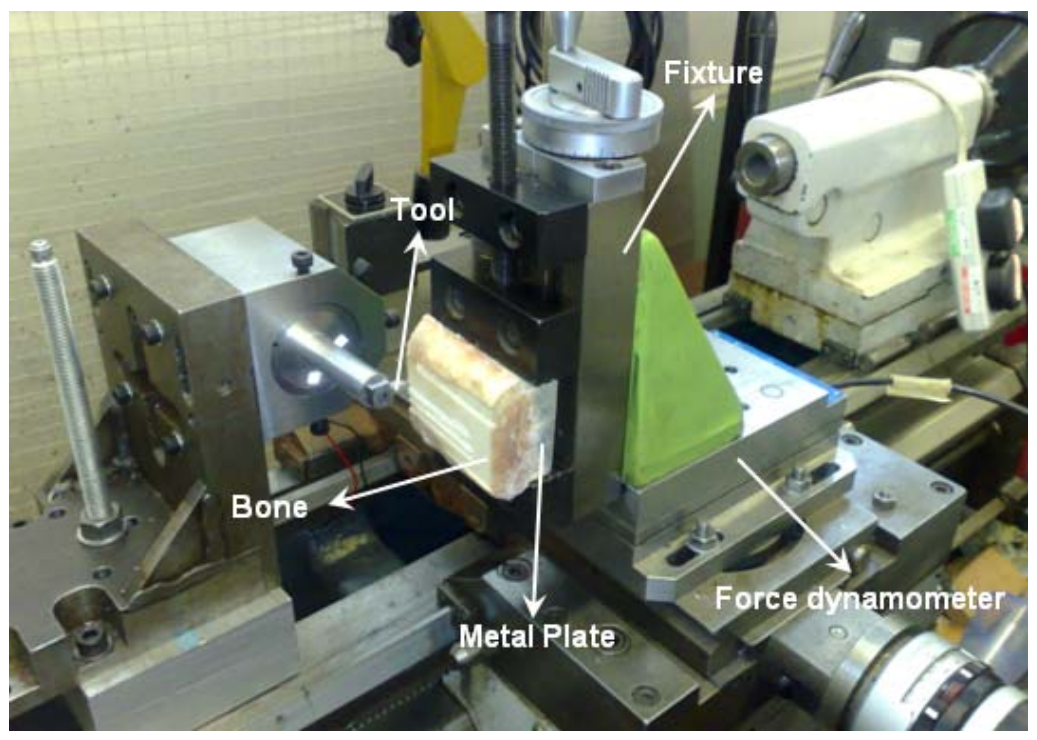

Fig. 8 


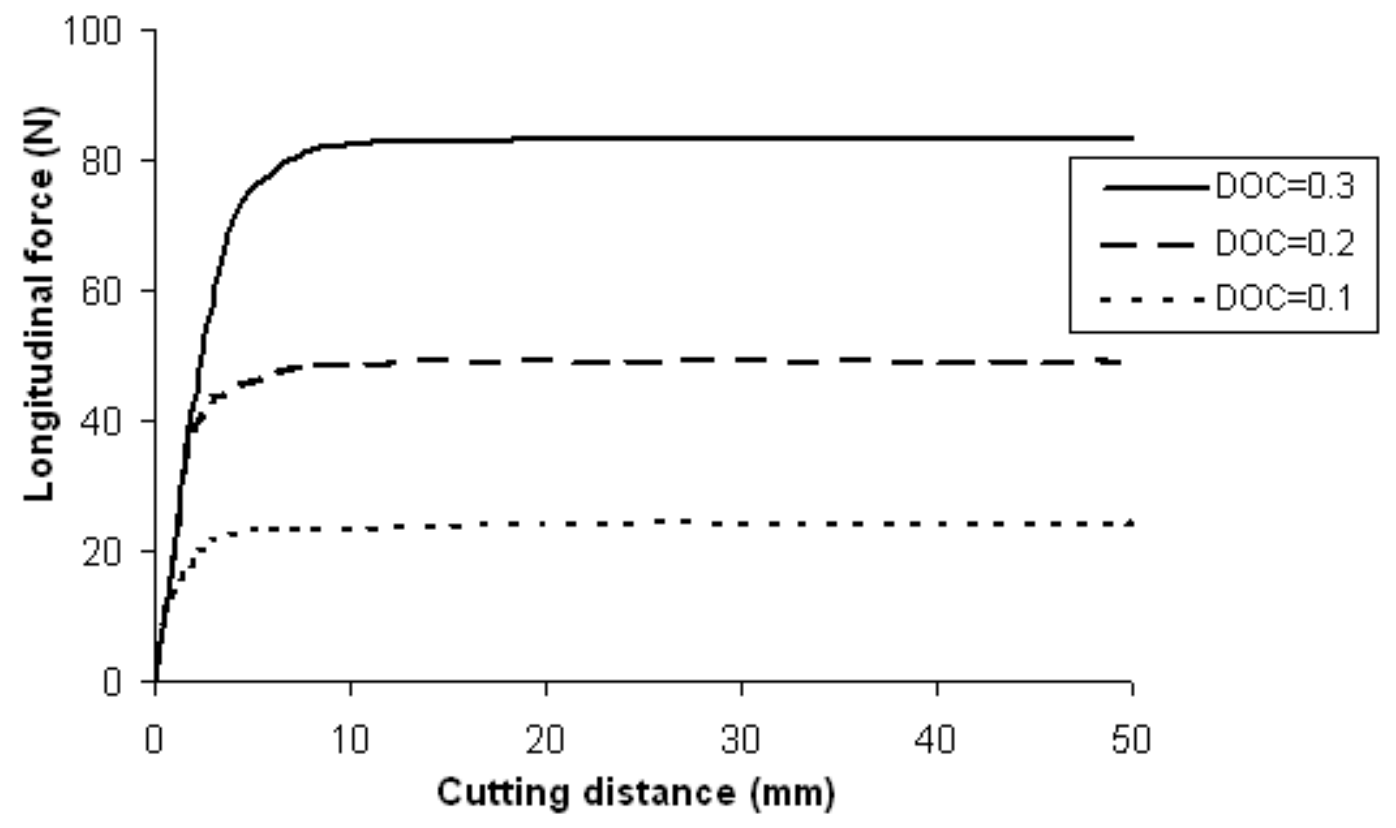

Fig. 9 


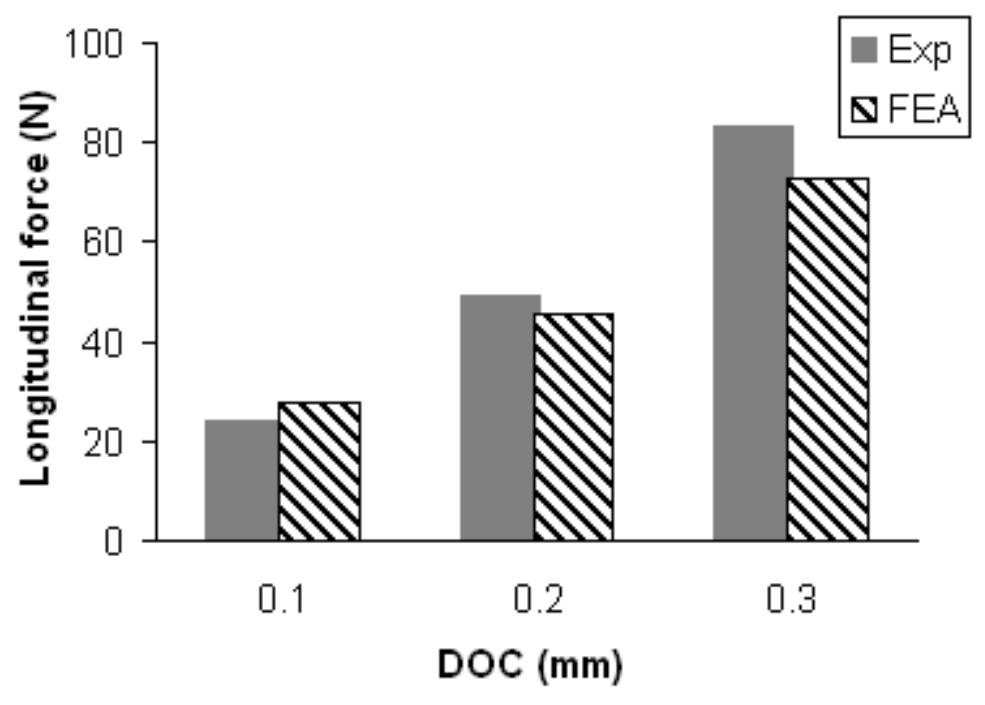

Fig. 10 